\title{
Produção intracelular de espécies reativas de oxigênio e fagocitose de Staphylococcus aureus por neutrófilos lácteos de quartos mamários com alta e baixa contagem de células somáticas
}

Paula Cristina Cardoso Molinari[a], José Augusto Ferronatto ${ }^{[a, b]}$, Maiara Garcia Blagitz ${ }^{[a]}$, Alice Maria Melville Paiva Della Libera ${ }^{[a]}$, Camila Freitas Batista ${ }^{[]]}$, Fernando Nogueira Souza ${ }^{[]]}$

\footnotetext{
[a] Veterinary Clinical Immunology Research Group, Departamento de Clínica Médica, Faculdade de Medicina Veterinária e Zootecnia, Universidade de São Paulo (USP), São Paulo, SP, Brasil

[b] Universidade do Oeste de Santa Catarina (UNOESC), Xanxerê, SC, Brasil
}

*Autor correspondente

e-mail: jose_augustoferronatto@hotmail.com

\section{Resumo}

A mastite é a inflamação da glândula mamária, frequentemente causada por bactérias. É a doença de maior impacto econômico na pecuária leiteira devido à redução na produção e qualidade do leite, uso de antimicrobianos, descarte do leite e maior demanda de mão de obra. A abordagem imunológica certamente tem potencial prognóstico, preventivo e terapêutico. Portanto, a melhor percepção da função dos neutrófilos pode aprofundar nosso conhecimento da resposta imune da glândula mamária e subsidiar ferramentas de seleção de animais resistentes a infecções intramamárias, aumentando a produtividade e lucratividade da atividade leiteira. 0 presente estudo utilizou 112 amostras provenientes de quartos mamários de 28 vacas Holandesas, que foram divididas em amostras de leite com baixa ( $\mathrm{n}=72 ; \leq 2 \times 10^{5}$ células $\left.\mathrm{mL}^{-1}\right)$ ou alta ( $\mathrm{n}=40 ; 2 \times 10^{5}$ células $\mathrm{mL}^{-1}$ ) contagem de células somáticas (CCS). A porcentagem de neutrófilos $\left(\mathrm{CH} 138 \mathrm{~A}^{+}\right)$ no leite, a produção intracelular de espécies reativas de oxigênio (ERO) e a fagocitose de Staphylococcus aureus pelos neutrófilos do leite foram avaliadas por citometria de fluxo. A distribuição dos dados foi inicialmente verificada pelo teste de Kolmogorov-Smirnov. Para a comparação entre os grupos, empregou-se o teste T de Student para amostra paramétricas e o teste de Mann-Whitney para amostras não paramétricas. Além disto, os valores preditivos das funções neutrofílicas (sensibilidade, especifidade e o índice Younden) foram determinados utilizando o limiar de CCS $\leq 2 \times 10^{5}$ células $\mathrm{mL}^{-1}$ como proveniente de quartos mamários

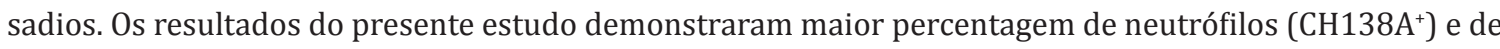
neutrófilos que produziram ERO em amostras de leite com alta CCS $\left(\%\right.$ CH138A ${ }^{+} 21.57 \pm 14.72, \mathrm{P}=0,0003$; $\%$ ERO $73.83 \pm 24.18 ; \mathrm{P}=0,008)$ do que em vacas com baixa CCS $(\%$ CH138A+12.57 $\pm 12.87 ; \%$ ERO 64.77 \pm 22.77 ). Por outro lado, a intensidade de fagocitose de $S$. aureus por neutrófilos foi maior em amostras de 
leite com baixa CCS (176.5 \pm 89.92, $\mathrm{P}=0,003)$ do que em amostras de quartos mamários com alta CCS (125.7 \pm 78.31 ), demonstrando maior atividade funcional destas células neste grupo. No entanto, não se observou diferença estatística entre os grupos na porcentagem de fagocitose e intensidade de produção de ERO pelos neutrófilos lácteos. A avaliação das funções neutrofílicas para o diagnóstico da mastite não apresentou valores de sensibilidade e especificidade altos, que foram confirmados pelo baixo índice Youden, portanto não podem ser indicados para o diagnóstico da mastite bovina. No entanto, os resultados do presente estudo reforçam a ideia de que os neutrófilos do leite com menor capacidade fagocítica podem ser associados à alta CCS, e podem ser considerados como ferramenta para identificar animais mais susceptíveis a infecções intramamárias. 